\title{
Reflexões acerca da atuação do agente comunitário de saúde nas ações de saúde bucal
}

\author{
Reflections around the performance of community health agents \\ in oral health strategies
}

Ana Larissa Fernandes de $\mathrm{H}_{\text {olanda }}{ }^{1}$

Aldenísia Alves de Albuquerque Barbosa ${ }^{1}$

Ewerton William Gomes Brito ${ }^{1}$

${ }^{1}$ Centro deFormação de

Pessoal para os Serviços de

Saúde"Dr. M anoel da Costa

Souza" (CEFOPE). Av.

Alexandrino deAlencar

1850, Tirol. 59015-350

Natal RN.

Imafaldo@bol.com.br
Abstract The Community Health Agent $(\mathrm{CHA})$ has traditionally been linked to doctors and nurses, being considered exclusive "property" of these professionals. Historically, oral health tended to operate isolated, disconnecting the mouth from the rest of the body and the individual from his environment. The Family Health Program (FHP) points to important changes in the organization of services as well as in the work process. One of the differences is the teamwork joining different professionals, including oral health which was previously excluded. The objective of the study is to show the experience of the $\mathrm{CHA}$ qualifying course, which allowed the entrance of different professional categories into teaching. The course included three odontologists as lecturers, and $\mathrm{CH} \mathrm{A}$ recognized other individuals as health team members, as well as expand the view of its rolewithin oral health. The professors also had their practices modified, given that they could understand the often ignored suffering and limitations of the $\mathrm{CHAs}$. Key words CHA, Oral health, Team, Family Health Program.
Resumo 0 agentecomunitário desaúde(ACS) tradicionalmente esteve mais vinculado ao profissional de enfermagem e ao profissional médico para realização das suas atividades práticas, sendo visto como um el emento de "propriedade" exclusiva desses profissionais da saúde. A saúde bucal historicamente tendeu a trabalhar isoladamente, separando a boca do resto do corpo e o indivíduo do seu meio ambiente. 0 Programa Saúde da Família (PSF) aponta para importantes mudanças na organização dos serviços e no processo de trabalho. U m dos diferenciais é o trabal ho de diversos ti pos de profissionais em equipe, inclusive a saúde bucal, que até então estava excluída. Este trabalho objetiva mostrar a experiência do curso de qualificação do ACS, que possibilitou a diversidade de categorias profissionais de nível superior, na docência. 0 curso contou com três docentes odontólogos; nele, foi possível para o ACS reconhecer outros atores como participantes da equipe desaúde, além de ampliar sua visão em relação ao seu papel na saúde bucal. 0 s docentes também ti veram suas práticas modificadas, uma vez que passaram a entender melhor a angústia elimitações dos ACS, muitas vezes ignoradas.

Palavras-chave ACS, Saúde bucal, Equipe, Programa Saúde da Família. 
Introdução

A crise da assistência à saúde, como consequência do modelo técnico-biologicista hegemônico, estimulou o M inistério da Saúde a desenvolver programas segundo a lógica da abordagem familiar, com estímulo às ações de promoção e proteção à saúde. Esta estratégia foi iniciada em junho de 1991, com a implantação do Programa de Agentes Comunitários de Saúde (PACS) e visava contribuir para a melhoria da qualidade de vida da população, investindo maciçamente em ações educativas individuais e coletivas, supervisionadas por um enfermeiro e com suporte assistencial de um profissional médico para cada equipe formada ${ }^{1}$.

Os resultados satisfatórios obtidos através do PACS estimularam o M inistério da Saúde a ampliar a abrangência deste programa, através da criação do Programa Saúde da Família (PSF). Assim, as primeiras equipes multidisciplinares do PSF compostas por um médico, um enfermeiro, um auxiliar deenfermagem - foram formadas em 1994, incorporando e ampliando a atuação dos agentes comunitários de saúde?.

De acordo com o documento oficial do M inistério da Saúde, o PSF reafirma eincorpora os princípios básicos de Sistema Ú nico de Saúde (SUS): a universalidade, descentralização, integralidade e participação da comunidade. Propõe reorganizar a prática assistencial a partir de novas bases em substituição ao modelo tradicional de assistênciae tem como princípios, o caráter substitutivo, a integralidade e a hierarquização, a territorial ização e adstrição da clientela ea equipe multiprofissional ${ }^{3}$.

M esmo tendo a integralidade nos seus princípios, a inclusão das Equipes de Saúde Bucal (ESB) às equipes de saúde da família, já existentes, ocorreu em outubro de 2000, seis anos após a criação do PSF, tendo como objetivos principais a melhoria dos índices epidemiológicos de saúde bucal ea ampliação do acesso da população brasileira às ações a ela relacionadas. A inclusão da saúde bucal no Programa Saúde da Família foi louvável e importantíssima para o progresso da odontologia como profissão no Brasil e da saúde bucal como condição de cidadania dos brasileiros4.

Durante muito tempo, as práticas odontológicas foram centradas no atendimento da demanda espontânea, com enfoque individual e abordagem tecnicista. A realização dessas práticas não se dava a partir de um planejamento e estavam voltadas para a lógica de mercado ${ }^{5}$. H istoricamente, a odontologia se configurou dentro dos conceitos ideológicos do paradigma flexneriano, formando profissionais capazes de proporcionar atenção cada vez mais especializada para os setores privilegiados da sociedade, reforçando, por essa via, um sistema excludente, eti lista, dissociado dos interesses da maioria da populaçãa ${ }^{6}$.

Atualmente, e com o advento da inclusão da saúde bucal no Programa Saúde da Família, o perfil esperado do cirurgião-dentista mudou e deve incluir, entre outras coisas, noções de epidemiologia, conhecimentos de saúde pública e o desenvolvimento do trabalho em equipe ${ }^{7}$. No entanto, percebe-se uma dificuldade de integração dos odontólogos nestas equipes, condicionada a sua formação acadêmica desvinculada dos problemas sociais da população, desvalorizada por estudantes e professores que adotam o desenvolvimento de conteúdos técnicos fortemente ancorados no interior do ambulatório-escola, sendo esteo lugar onde o tecnicismo é produzido, e reproduzido, refletindo uma prática meramente positivista ${ }^{8}$.

Por outro lado, a formação original do ACS, vinculada inicialmenteà categoria de enfermagem emédica, contribui para o distanciamento de relações entre dentistas e ACS, dificultando a realização de ações de saúde bucal entre estes, tornandoas menos efetivas, tendo em vista que o ACS atua como um elo entre as necessidades de saúde das pessoas e o que pode ser feito para a melhoria das condições de vida da comunidade' ${ }^{9}$, sendo um segmento efetivo da produção dos serviços, que se apresenta não apenas como suporte para gerar determinadas ações em saúde, mas, também, como peça essencial na organização da assistência ${ }^{10}$.

Desta forma, este trabalho tem como objetivo relatar a experiência de três cirurgiões-dentistas como docentes do curso de qualificação dos agentes comunitários de saúde, ressaltando seus desafios, suas estratégias e seus avanços no anseio por trocas de experiências e na busca de um sentido amplo de integralidade e trabalho em equipe.

\section{Curso dequal ificação: ampliando o olhar}

De acordo com a Lei no 10.507 de 10/06/2002, na qual fica criada a profissão de agente comunitário de saúde, um dos requisitos básicos para desempenhar essepapel éa conclusão do curso dequalificação básica para a formação do ACS. No ano de 2004, o M inistério da saúde lançou o referencial curricular para curso técnico de agentes comunitários de saúde, propondo a preparação de técnicos de nível médio que deverão atuar junto às equipes multiprofissionais desenvolven do ações de cuidado e proteção à saúde de indivíduos e grupos sociais, em domicílios e coletividades. São menciona- 
dos também a atuação intersetorial e o desenvolvimento de ações de promoção da saúde ${ }^{11}$. 0 curso passa a ser estruturado com uma carga horária mínima de 1.200 horas e seu acesso está previsto através de três etapas: etapa formativa I, para todos os ACS inseridos no SUS, independentemente de escolarização e com carga horária de 400 horas; etapa formativa II, para ACS que concluíram a etapa formativa I eque concluíram ou estão cursando o ensino fundamental, com a carga horária de 600 horas; e etapa formativa III, para concluintes das etapas anteriores que estão cursando ou concluíram o ensino médio, com carga horária de 200 horas. A formação deve valorizar a singularidade profissional deste trabalhador, tendo as características do seu perfil social, a promoção da saúde e a prevenção de agravos como eixos estruturantes e integradores do processo formativo ${ }^{11}$.

No Estado do Rio Grande do Norte, a primeira etapa do curso de qualificação do ACS foi realizada no período de junho a outubro de 2005, oferecida pelo Centro de Formação de Pessoal para os Serviços de Saúde "Dr. M anoel da Costa Souza” (CEFOPE), que possibilitou a inclusão de diversas categorias profissionais de nível superior na docência, tais como enfermeiros, dentistas, assistentes sociais, entre outras.

Os autores deste artigo estavam diretamente ligados a esse processo de formação, no papel de docentes do curso de qual ificação, em áreas de atuação diferentes. Todos os docentes participaram, inicialmente, de uma capacitação pedagógica com carga horária de quarenta horas, mediada por uma pedagoga. Apesar de a seleção ter sido realizada através da análise decurrículos, priorizando os profissionais com formação em saúde pública e a experiência docente, foi intriganteperceber a surpresa inicial de al guns colegas de outras categorias profissionais com a presença de dentistas no quadro de docentes, como se não entendessem a relação existente entre os ACS e a odontologia ou mesmo questionassem a capacidade pedagógica e o conhecimento generalista necessário para atuar na docência. Esse fato pôde ser superado, com o passar dos dias, nas discussões e trabalhos em grupos.

Os três docentes em questão assumiram turmas em doismunicípios da área metropolitana, Parnamirim eSão Gonçalo do Amarante. Todos tinham em comum o mesmo plano decurso ea prática pedagógica problematizadora, na qual docentes e alunos constroem a aprendizagem baseados na observação da realidade, identificam os problemas vivenciados e, fundamentadosno conhecimento científico já produzido, são estimulados a buscar soluções para a transformação da realidade e de si mesmos.
Desta forma, as aulas foram ministradas de maneira dinâmica, através da realização de seminários, discussões coletivas, dramatizações e exposições dialogadas facilitadas pelos docentes.

Iniciadas as atividades em sala de aula, a surpresa, que já havia aparecido em um primeiro momento, seconfigurou novamente nos semblantes dos alunos, pois estes esperavam por algum profissional da enfermagem na docência. A presença de um odontólogo como docente causou espanto, desconfiança e, em alguns casos, insegurança. Era difícil a compreensão deter um "dentista" como "professor". Tal fato éperfeitamentecompreensível, tendo em vista a Portaria № 1.886, de dezembro de 1997, do M inistério da Saúde ${ }^{12}$, que aprova as Normas e Diretrizes do PACS e PSF e estabelece entre outras atividades que são de competência do enfermeiro o planejamento ea coordenação da capacitação e educação permanente dos ACS, ressaltando que estas devem ser executadas com a participação dos demais membros da equipe de profissionais do serviço local de saúde.

Ademais, a formação acadêmica dos cirurgiões-dentistas leva os mesmos a desenvolverem, na maioria das vezes, um trabalho meramente técni$\mathrm{co}$, restrito à cavidade bucal, portanto descompartimentalizado do corpo e dos diversos "especialistas" que tratam das diversas partes desse indivíduo. 0 reflexo dessa atividade é percebido pelos demais componentes das equipes de saúde, inclusive pelosACS, aumentando o distanciamento destes profissionais e elaborando no senso comum uma idéia de que o dentista é incapaz de realizar outras tarefas que transcendam às atividades técnicas odontológicas.

0 trabalho em equipe foi um dos primeiros temas abordados e possibilitou aos alunos uma visão mais ampla sobre o sentido de equipe, quem eram os atores destas equipes e quais os seus papéis. 0 trabalho em equipe surge como uma estratégia para redesenhar o trabal ho e promover a qualidade dos serviços. Entre estes processos, podemos citar o planejamento de serviços, o estabelecimento de prioridades, a redução da duplicação dos serviços, a geração de intervenções mais criativas, a redução de intervenções desnecessárias pela falta de comunicação entre os profissionais, a redução da rotatividade, resultando na redução de custos, com a possibilidade de aplicação e investimentos em outros processos. Entretanto, apesar dos benefícios apontados, algumas dificuldades e problemas vêm sendo identificados ${ }^{13}$.

As atribuições do ACS constituiu um tema capaz de promover uma reflexão sobre as suas práticas diárias. Dentre as atividades desenvolvidas, 
os agentes comunitários de saúde relataram realizar, em suas visitas domiciliares, um trabalho de prevenção, orientando os pacientes diabéticos, hipertensos e gestantes. Procurando solucionar os problemas de acordo com as prioridades de cada família, também fazia parte das atividades dos agentes transmitirem orientações no que se refere ao lixo, à alimentação, além de esclarecer as mães de crianças menores de dois anos quanto à desnutrição e à vacinação. Durante as discussões, os próprios alunos perceberam que as suas atuações poderiam ser mais amplas dentro de uma equipe, que a promoção e a manutenção da saúde bucal faziam parte das suas atribuições, assim como a boca estava inserida em um corpo equeesse corpo formava um indivíduo, que precisava ser olhado e cuidado como um todo. 0 profissional de saúde compromissado com o usuário precisa fixar o olhar além do corpo que está à sua frente. 0 olhar deve se dirigir para a produção de cuidado daquele sujeito. Portanto, para o profissional que tece 0 ato de cuidar no seu cotidiano, é necessário estar sempre ampliando suas ações ${ }^{14}$.

Outros importantes temas foram discutidos ( políticas públicas de saúde, processo saúde-doença, educação em saúde, pluralidade cultural, etc.) e, durante esse processo, as angústias, as dúvidas e os questionamentos foram compartilhados em sala de aula.

$\mathrm{Na}$ grande parte dos relatos, foi possível notar que os ACS possuíam alguns conhecimentos em relação à vacinação das crianças, pesagem, doenças crônicas (diabetes, hipertensão, etc.) einfectocontagiosas (tuberculose, hanseníase, etc.), ao contrário da saúde bucal, em que muitos não detinham informações básicas necessárias à prevenção e controle das principais doenças bucais (cárie e doença periodontal). Além de não perceberem, muitas vezes, a importância do fator social no aparecimento destas patologias.

No início do curso, quando abordados sobre o seu papel na odontologia, os ACS relatavam que estava voltado exclusivamente para a marcação de consultas, o que achavam delicado, pois não detinham noções de saúde bucal e acabavam sendo repreendidos por marcarem procedimentos em dias que não eram os determinados: Aí a doutora manda marcar limpeza, equando chega épara obturar, como vou saber? (ACSI, SGA-RN)

$M$ arquei para uma criança uma vez o flúor eera restauração. (ACSII, SGA-RN)

Como consequência direta destes relatos, foi possível uma reflexão, não apenas dos alunos, mas também por parte dos docentes, sobre como os odontólogos estavam inseridos em um sentido de equipeeseestes entendiam as dificuldades dosACS em desenvolver suas atividades, uma vez que, delegando a responsabilidade da marcação de consultas aos ACS, seria necessário um mínimo de conhecimento acerca da odontologia para obterem sucesso nesta atividade.

Quando questionados sobre a realização de atividades educativas em saúde bucal, a grande maioria relatou que desenvolviam sim, esporadicamente, esse tipo de atividade, e posteriormente perceberam que suas atitudes, algumas vezes, estavam desvinculadas da realidade da população: Falo que tem que escovar os dentes depois das refeições, mas agora sei que é difícil. A água é difícil. (ACSIII, SGA-RN)

A dificuldade de diálogo com o odontólogo foi vista como um grande entrave nos planejamentos das atividades educativas: A doutora chega, atendee vai embora. Fica na sala dela com a auxiliar eémuito difícil participar das reuniões. (ACS IV, SGA-RN)

A dificuldade de integração entre a equipe de saúde bucal, por si só já fragmentada originalmentepelo M inistério da Saúde, eosACS também pôde ser claramenteevidenciada no momento em foram abordados os temas comunicação em saúde e educação em saúde. A proposta do curso era estimular os alunos ao desenvolvimento de práticas educativas em que fossem considerados aspectos importantes para se estabelecer uma comunicação clara, bilateral, na qual o "educador" entra em sintonia com crenças e valores da comunidade, percebendo suas necessidades e buscando sensibilizá-los à mudança de hábitos considerados não saudáveis.

A pós uma semana de problematização sobreo tema, dramatizações que envolviam as práticas educativas dos ACS nas suas comunidades, leitura dos textos propostos pelo CEFOPE e exposição dialogada sobre o tema em questão, os alunos tiveram com tarefa vivencial: desenvolver uma atividade educativa, nas suas microáreas, colocando em prática o conhecimento oriundo do curso. A atividade deveria ser apresentada em sala de aula antes que fosse desenvolvida com a comunidade; assim, poder-se-ia observar possíveis falhas inerentes à comunicação e/ou ao conteúdo teórico.

Assim, formaram-se vários grupos que abordaram diversos temas de saúde, inclusive saúde bucal. Os alunos optaram por desenvolver uma palestra educativa para um grupo de crianças do ensino fundamental em uma das escolas da comunidade. Observou-se que os recursos visuais, a linguagem, o tempo de duração da atividade e o horário escolhido foram bastante pertinentes, denotando a assimilação do conteúdo discutido na sala de aula anteriormente. Entretanto, percebia-secla- 
ramente a insegurança dos ACS em repassar as informações relativas à saúde bucal. A pós a apresentação do grupo, formou-se uma roda de discussão a fim de analisar os aspectos negativos e positivos da atividade. Segundo os alunos que desenvolveram a atividade e os demais que a assistiram, existe uma carência muito grande de conhecimento acerca destetema, atribuída à falta de treinamentos proporcionados pela Secretaria de Saúde e pela própria equipe de saúde bucal que se distancia dos demais membros da equipe, realizando um trabalho desintegrado dos demais membros da equipe do PSF, conforme pode ser observado nos relatos: 0 problema, professor, é que eles mesmos ( os dentistas) se afastam da gente! Chegam ese trancam naquela sala e a gente tem vergonha até de falar! (ACS, Parnamirim-RN)

A Secretaria faz curso 0 ano inteiro de tuberculose, hanseníase, diabetes, mas a gente nunca teve nenhum treinamento em saúde bucal, o que a gente sabe é porque aprendeu ouvindo eles falarem nas escolas. (ACS II, Parnamirim-RN)

0 processo de trabalho do cirurgião-dentista raramente tem se inserido em práticas partilhadas com profissionais de outras áreas, revelando uma escassa familiaridade com o trabalho em equipe. Assim, suas ações ainda permanecem isoladas. Além do mais, são perceptíveis os indícios dessa prática isolada em contextos como o da estrutura dos serviços de saúde, que reforça a divisão do trabalho através de especialidades estanques que pouco interagem, - ou nas instituições de ensino e formação do cirurgião-dentista, queainda priorizam o tecnicismo e o biologismo, em detrimento de qualquer possibilidade de integração das disciplinas ${ }^{14}$.

É no trabalho em equipe que existea possibilidade da troca e do projeto em comum das diversas áreas profissionais envolvidas. A especificidade da odontologia é muito importante e necessária, desde que inserida em um campo comum às várias profissões. Este é o acordo que possibilita o trabalho em equipe em um dado contexto e cotidiano, desde que o dentista não reproduza uma prática isolada, mas passe a atuar em uma perspectiva interdisciplinar, que pressupõe um fator de transformação e de mudança social, como proposto por Fazenda ${ }^{15}$.

A inclusão da saúde bucal no Programa Saúde da Família é um veículo da história que pode carrear futuro afora, elementos do "novo" gerados num processo rico de recriação das situações pre sentes, em busca de um esperado estado de bemestar em saúde bucal, já possível de ser vivenciado pelos cidadãos brasileiros. Por outro lado, como veículo da história, essa inclusão também pode carrear elementosjá esgotados do "vel ho", os quais, travestidos de "novos", sob o manto da Saúde da Família, acabarão por mortificar as possibilidades objetivas de superação das situações presentes 4 .

A importância de uma capacitação constante dos ACS sobre os temas que envolvem os principais problemas da sua comunidade foi colocado em discussão. E notável foi perceber o grande entusiasmo quando essa possibilidade foi relatada. $N$ esse sentido, o treinamento desses agentes deve muni-los de conhecimentos diversos em torno da questão do processo de saúde-doença, incorporando, além da perspectiva biomédica, outros saberes que os habilitem nesse processo de interação cotidiana com as famílias e no reconhecimento de suas necessidades.

O ACS tem uma missão social bem clara, pois é alguém intei ramente identificado com sua própria comunidade, com os mesmos valores, costumes e linguagem, cuja capacidade de liderança se reverte em ação comunitária em prol da melhoria das condições de vida e de saú de, apoiada pela ação governamental ${ }^{16}$. A formação desses profissionais deverá valorizar a singularidade profissional deste trabalhador, tendo as características do seu perfil social, a promoção da saúde ea prevenção de agravos como eixos estruturantes e integradores do processo formativo.

De acordo com M endonça ${ }^{17}$, os conhecimentos exigidos no processo de trabalho do ACS são bastante complexos e diversificados, apontando também ao fato destes conhecimentos transcenderem o campo da saúde por requererem a aprendizagem de aspectos que estão presentes nas condições de vida da população eque exigem uma atuação intersetorial. O papel social do ACS foi enfatizado durante todo o curso e o propósito de formar sujeitos pensantes sobre as suas práticas e capazes de transformá-la foi estimulado. Sujeitos que pensem sobrea doença depois de observarem as suas causas e a sua prevenção e incorporem a integralidade do indivíduo para o sentido de cuidado ser desenvolvido. A ampliação do olhar dos alunos em relação à saúde foi o foco das discussões, além da grande importância destes profissionais como atores do processo de construção desta saúde.

\section{Consideraçõesfinais}

A importância do trabalho em equipeno PSF éressaltada, principalmente, pelo aspecto de integralidade nos cuidados de saúde. Considerado um dos princípios doutrinários do Sistema Único de Saúde (SUS), a integralidadereveste-se de uma importân- 
cia estratégica ímpar para a consolidação de um novo modelo de atenção à saúde no Brasil.

Para consolidar, na prática, esse novo modelo, torna-se necessária a presença de cirurgiões-dentistas, assim como todos os demais profissionais integrantes deuma equipemultiprofissional, como é o caso do Programa Saúde da Família (PSF), nos cursos de educação continuada, como estratégia de promoção à saúde, de forma que possam ser agentes transformadores de um paradigma, ainda hegemônico, que dissocia (desintegra) a equipe e distancia os profissionais.

$\mathrm{Na}$ busca por essas mudanças, o papel das escolas formadoras surge como o alicerce, uma vez que essa formação deverá objetivar a preparação de futuros cirurgiões- dentistas, capacitando-os para entender, valorizar a desenvolver esse traba-
Iho em equipe, saindo do modelo tecnicista e biologicista, visando uma proposta de trabalho que entenda o individuo e a sociedade em seus múltiplos aspectos.

\section{Colaboradores}

ALF de Holanda eEWG Brito trabal haram na concepção do artigo e redação, assim como na pesquisa. AAA Barbosa participou da pesquisa e metodologia.

\section{Referências}

1. Brasil. Ministério da Saúde. Cadernos Saúde da Família. Brasília: M inistério da Saúde; 1996.

2. Santana ML, Carmagnani MI. Programa Saúde da Família no Brasil: um enfoque sobre os pressupostos básicos, operacionalização e vantagens. Saúde e Sociedade 2001; 10(1):33-54.

3. Roncalli AG, Araújo LUA. O Sistema Único de Saúde e os modelos assistenciais: das propostas alternativas à saúde da família. In: Ferreira MAF, organizador. Saúde bucal coletiva: conhecer para atuar. Natal: EDUFRN ; 2004. p. 261-286.

4. Zanetti CHG. Por um caminho sustentável para universalização da atenção básica: Saúde Bucal da Família com equidade e integralidade. Brasília: Universidade de Brasília; 2000.

5. Zanetti CHG, Lima MAU, Ramos L, Costa MABT. Em busca de um paradigma de programação local em saúde bucal mais resolutivo no SUS. Saúde para Debate 1996; 13:18-35.

6. Júnior AM. Modelos Assistenciais em saúde Bucal. In: Ferreira MAF, organizador. Saúde bucal coletiva: conhecer para atuar. Natal: EDUFRN; 2004. p. 277-286.

7. Moysés SJ, Silveira Filho AD. Saúde bucal da família; quando um corpo ganha uma boca. In: Silveira Filho $A D$, Ducci L, Simão M G, Gevaerd SP. Os dizeres da boca em Curitiba: Bocas M alditas, Boqueirão, Bocas saudáveis. Rio de Janeiro: CEBES; 2002.

8. Botazzo CA. Saúde bucal nas práticas coletivas de saúde. Brasília: Instituto de Saúde; 1994. [Série Tendências e Perspectivas em Saúde 1]

9. Nunes M O, Trod LB, Almeida BA, Homem, CR, M elo $\mathrm{MCl}$. O agente comunitário de saúde: construção da identidade desse personagem híbrido e polifônico. Cad Saude Publica 2002; 18:1639-1646.
10. Silva JA, Dalmaso ASW. Agente comunitário de saúde: o ser, o saber, o fazer. Rio de Janeiro: Fiocruz; 2002.

11. Brasil. Ministério da Saúde. Ministério da Educação. Referencial curricular para curso técnico de agentes comunitários de saúde: área profissional saúde. Brasília: Ministério da Saúde; 2004.

12. Brasil. Ministério da Saúde. Portaria ํㅡ 1.886, de 18 de dezembro de 1997. Aprova as Normas e Diretrizes do Programa de Agentes Comunitários de Saúde e do Programa de Saúde da Família. Diário O ficial da U nião 1997; 22 dez.

13. Pinho MC. Trabalho em equipe de saúde: limites e possibilidades de atuação eficaz. Ciências \& Cognição [periódico na Internet] 2006. Disponível em: http:// www.cienciasecognicao.org/artigos/v08/m326103.htm

14. Teixeira CBA. Dimensão cuidadora do trabalho de equipe em saúde e sua contribuição para a odontologia. Cien Saude Colet 2000; 11(1):45-51.

15. Fazenda ICA. Interdisciplinaridade: história, teoria e pesquisa. Campinas: Papirus; 1995.

16. Sousa M F. Agentes comunitários de saúde. Choque de Povo! São Paulo: Hucitec; 2001.

17. M endonça MHM. Profissionalização e regulação da atividade do agente comunitário de saúde no contexto da reforma sanitária. Trabalho, Educação e Saúde 2004; 2(2):353-365.

Artigo apresentado em 06/12/2006

Aprovado em 27/06/2007 